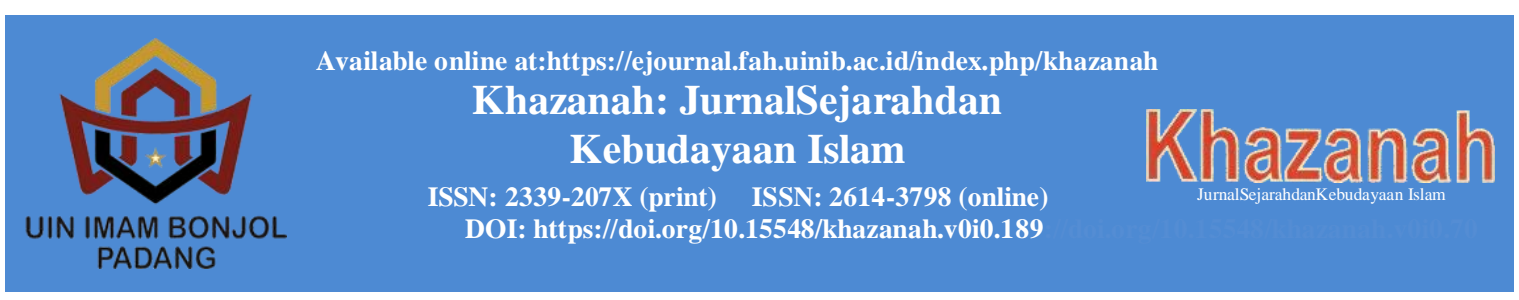

\title{
UPACARA ROKAT DALAM TRADISI MADURA: Tinjauan Living Hadist
}

\author{
Badrud Tamam \\ Universitas Islam Negeri Sunan Ampel Surabaya \\ tamampasca@gmail.com
}

\begin{abstract}
Islam is a religion with the universe spirit, that made it lives and thrives in diverse society.

When Islam developed outside of Arabia, it came into contact with other culture. In its interaction between Islam and other culture, creating a harmonization of islamic values with local cultures values. In the islamic scholarship this is known as the living hadist. One of the example is upacara rokat in the Madurese culture who has experienced Islamization. Origanlly, the upacara rokat came from a pre-islamic traditions.
\end{abstract}

Keywords: living hadist, rokat tradition, madurese culture

\begin{abstract}
Abstrak
Islam adalah agama yang memiliki spirit universal yang menjadikannya mampu hidup dan tumbuh subur di dalam masyarakat dunia yang beragam. Ketika Islam berkembang di luar Arab, ia mengalami persinggungan kebudayaan negeri lain. Terciptalah harmonisasi nilai-nilai keislaman dengan nilai-nilai kebudayaan setempat. dalam khazanah keislaman hal ini dikenal dengan istilah living hadisrt. Di antaranya upacara rokat dalam kebudayaan Madura yang kemudian mengalami proses islamisasi. Tradisi rokat berasal dari tradisis pra Islam. Melalui dakwah ulama Walisongo, tradisi tersebut kemudian diislamisasi.
\end{abstract}

Kata kunci: living hadist, tradisi rokat, kebudayaan Madura

\section{PENDAHULUAN}

Tradisi adalah sistem nilai yang muncul dalam praktek suatu masyarakat sebagai kebiasaan yang bersifat turuntemurun. Dari generasi ke generasi. Dalam hal ini, tradisi selalu berkembang sesuai dengan zamannya. Bahkan mengalami revolusi karena adanya proses adaptasi, asimilasi, akulturasi dengan kebudayaan atau pandangan lain. Dalam konteks keislaman, setelah meluasnya Islam hingga ke negeri-negeri di luar jazirah Arab, memunculkan fenomena adanya persinggungan antara ajaran Islam dengan kebudayaan yang berkembang di masingmasing negeri.

Sudah barang tentu, tidak sedikit dari kebudayaan-kebudayaan tersebut yang sama sekali tidak terdapat di negeri Arab. Hal ini juga menyebabkan para ulama yang menyiarkan Islam dihadapkan pada problematika keagamaan yang juga tidak pernah mereka alami dan hadapi sebelumnya. Dalam kondisi tersebut, 
mereka dituntut untuk dapat memecahkan setiap problematika yang muncul sehingga Islam dapat diterima oleh penduduk setempat.

Pada dasarnya, problematika tersebut sudah muncul begitu Nabi Muhammad SAW wafat. Ketika Nabi masih hidup semua problematika keagamaan dapat langsung ditanyakan pada Nabi, tidak demikian begitu beliau wafat. Dalam perkembangannya, problematika keagamaan pasca-Nabi ini kemudian memunculkan fenomena ijtihad, seperti yang dilakukan oleh sahabat Umar bin Khattab. Di antara problematika tersebut, ketika Umar bin Khattab tidak membagi harta rampasan perang berupa tanah, tetapi membiarkan tetap dipegang oleh pemilik asalnya. Ia memunculkan hukum lain, yaitu memberi kewajiban bagi pemilik tanah untuk membayar upeti.

Jelas, kebijakan Umar bin Khattab bertentangan dengan kebijakan Nabi yang membagikannya pada para sahabat. Ia juga pernah mengirim surat kepada Abu Musa al-Asy'ari, seorang qadhi Basrah, yang berisi instruksi untuk menggunakan atau mengadaptasi kebudayaan setempat dalam penyelesaian hukum.

Selain Umar bin Khattab yang menggunakan ijtihad dalam memutuskan hukum yang belum ada di zaman Nabi, ada sahabat Ali bin Thalib yang dikenal mengedepankan patokan al-hadist. Dua sosok sahabat ini kemudian dikenal dengan dua mazhab, yaitu mazhab Umari dan mazhab Alawi. Mazhab Umari dilanjutkan oleh Abdullah ibn Mas'ud dengan ciri khas fiqh al-ra'y. Sementara mazhab Alawi yang berpusat pada Ali bin Abi Thalib menekankan figh al-atsar atau juga dikenal dengan ahl al-hadist. Nantinya, dua mazhab dengan ciri khas penetapan hukum Islam masing-masing tersebut lalu berkembang dan berpolarisasi menjadi mazhab besar. Pola fiqh al-ra'y, diwakili oleh Imam Abu Hanifah, sesuai dengan pola fiqh al-ra'y, ia cenderung rasional dalam gagasan ijtihadnya. Sementara pola fiqh al-atsar, diwakili oleh Imam Malik ibn Anas. Sebagaimana prinsip fiqh al-atsar, lebih menekankan al-hadist dalam pengambilan hukum Islam. Lalu muncullah
Imam Syafii yang merupakan sintesa dari dua arus besar tersebut.

Dalam konteks modern di mana perkembangan Islam sudah mengglobal dan semakin jauh dari jazirah Arab, persinggungan Islam dengan kebudayaankebudayaan luar yang sama sekali berbeda dari Arab, kemudian melahirkan sebuah teori baru dalam upaya memaknai sebuah budaya dan korelasinya dengan nilai-nilai keislaman, yaitu apa yang dikenal living hadist.

\section{Rokat Pamengkang}

Salah satu dari sekian banyak tradisi yang berakar dari kebudayaan setempat dan mengalami islamisasi adalah upacara rokat. Upacara adat ini merupakan tradisi yang berkembang di kepulauan Madura. Upacara ini merupakan suatu upacara adat yang diselenggarakan demi meraih keselamatan dan terhindar dari segala marabahaya, seperti penyakit, wabah, bencana dan marabahaya lainnya. Dalam upacara ini, dilakukan sesaji, seperti kepala ayam, sapi atau kambing, aneka makanan dan buah-buahan yang dibuang ke laut.

Dalam tradisi aslinya sejak zaman pra-Islam, melalui tradisi rokat, orangorang Madura menyapa para leluhur agar senantiasa memberkati kehidupan mereka. Dengan demikian, melalui melalui sarana meminta berkah nenek-moyang melalui upacara rokat, masyarakat Madura berharap dapat terhindar dari segala marabahaya, baik di darat maupun di laut. Masyarakat Madura meyakini bahwa leluhur mereka meskipun telah meninggal, tetapi masih bisa diminta pertolongan. Terdapat beberapa jenis rokat, yaitu rokat yang dilakukan dalam rangka untuk kepentingan pribadi (individual), seperti rokat pamengkang, tanaman atau pandhaba; sedangkan rokat yang dilakukan dalam rangka kepentingan masyarakat umum (komunal), seperti munculnya wabah penyakit, rokat tase dan lain sebagainya.

Di sini, yang akan penulis bahas secara khusus adalah rokat pamengkang. Rokat pamengkang ini merupakan upacara adat yang diselenggarakan untuk 
mendoakan tanah warisan leluhur. Mereka berharap agar tanah warisan leluhur tersebut tidak menimbulkan malapetaka bagi pemiliknya, sekaligus merupakan pengungkapan rasa terima kasih kepada leluhur. Gelar upacara ini juga dimaksudkan agar tanah tersebut tidak menimbulkan malapetaka bagi pemiliknya.

Dalam praktek upacara rokat pamengkang, di dalamnya berisi pembacaan surat Yasin, dzikir-dzikir khusus rokat pamengkang serta berdoa bersama. Setelah itu, menyembelih ayam kampung, dagingnya dibagikan kepada sanak-tetangga, darah dan bulunya dikubur bersama dalam lubang yang digali di tanah warisan. Pengkuburan darah dan bulunya tersebut sebagai simbol keselamatan dari hal-hal yang buruk.

Hadits $\begin{gathered}\text { tentang } \\ \text { Sokatan } \\ \text { Sebagaimana telah dipaparkan }\end{gathered}$ sebelumnya, tradisi rokatan sejatinya merupakan suatu kebudayaan masa sebelum masuknya agama Islam ke Madura, yaitu ketika agama Hindhu-Budha maupun masa animisme-dinamisme yang masih dianut oleh masyarakat Madura. Ketika agama Islam mulai berkembang di Madura, tradisi rokatan masih dipertahankan, tetapi unsurunsur utama di dalamnya telah diperbarui dengan nilai-nilai tauhid, seperti digantinya tujuan doa kepada roh-roh leluhur kepada doa-doa yang ditujukan kepada Allah SWT.

Lalu, apakah praktek demikian dibenarkan dalam Islam? Secara khusus praktek upacara rokat tidak akan ditemukan pada zaman Nabi Muhammad SAW. Dengan demikian, kita tidak akan menemukan landasan syariatnya secara tekstual. Namun demikian, sebagaimana telah diulas sebelumnya, rokat pamengkang telah mengalami proses islamisasi. kemasan rokatnya masih tetap sebagaimana sebelumnya, namun kita tidak lagi menemukan ritual-ritual yang bertentangan dengan syariat Islam. Aspek-aspek seremonial upacara maupun isinya telah berwarna Islam, yaitu diisi dengan pembacaan Surat Yasin bersama para tetangga, kemudian dipungkasi dengan doadoa khusus rokat tanah pamengkang. Doadoa tersebut tidak lagi menjadikan roh-roh leluhur sebagai tumpuan keselamatan dari segala marabahaya, tetapi menjadikan Allah sebagai kiblat doa sebagai pencipta alam semesta yang dapat memberikan keselamatan.

Dengan kata lain, telah terjadi perubahan niat dan motivasi dalam proses penyelenggaraan upacara adat yang dipraktekkan oleh masyarakat Madura. Jika sebelumnya masyarakat Madura menggelar upacara rokat dengan niat dan motivasi untuk mencari keselamatan kepada roh-roh leluhur, kini setelah mengalami proses islamisasi, maka upacara rokat diniatkan untuk mencari keselamatan hanya kepada Allah SWT. Hal ini juga berarti bahwa masyarakat Madura telah mengalami yang namanua hijrah kebudayaan, yaitu dari kebudayaan yang mengandung nilai-nilai jahiliyah menuju kebudayaan yang memiliki watak dan spirit ketauhidankeislaman.

Jika menelusuri teks-teks hadist secara umum, proses terjadinya perubahan niat dan hijrah kebudayaan melalui upacara rokat tersebut, terdapat sebuah hadist yang menjelaskan bahwa hukum semua perbuatan atau amal adalah tergantung pada niat yang melandasinya. Hadist yang dimaksud tersebut adalah diriwayatkan oleh Imam Bukhari dalam Kitab Iman, No 52. Hadist ini juga diriwayatkan oleh Imam Muslim No. 3530 dalam kitab Kepemimpinan. Berikut bunyi hadist tersebut:

"Telah menceritakan kepada kami, Abdullah bin Maslamah berkata, telah mengabarkan kepada kami Malik dari Yahya bin Said dari Muhammad bin Ibrahim dari Alqamah bin Waqash dari Umar, bahwa Rasulullah SAW bersabda: "Semua perbuatan tergantung niatnya. Dan (balasan) bagi tiap-tiap orang (tergatung) apa yang diniatkan. Barangsiapa niat hijrahnya karena Allah dan Rasul-Nya, maka hijrahnya adalah kepada Allah dan Rasul-Nya. Barangsiapa niat hijrahnya karena dunia yang ingin digapainya atau karena seseorang perempuan yang dinikahinya maka hijrahnya adalah kepada yang dia niatkan." 
Dalam konteks hadist tersebut, rokat pamengkang yang semula merupakan tradisi pra-Islam, mengalami titik kunci pada perubahan niat asalnya, yaitu niat meminta keselamatan pada roh-roh leluhur. Setelah mengalami proses islamisasi, landasan niat tersebut kini berubah, yaitu niat meminta keselamatan hanya pada Allah SWT sebagai pencipta kehidupan. Sebagai pencipta baik dan buruk di dalam kehidupan di dunia. Maka, berdasarkan landasan niat dilakukannya rokat pamengkang, memiliki kesesuaian dengan makna dalam hadist yang diriwayatkan oleh Imam Bukhari di atas.

Dalam hal ini, adanya perubahan landasan niat dari roh-roh leluhur kepada Allah SWT-yang juga diikuti oleh isi upacara yang di dalamnya diadakan pembacaan surat Yasin, dizikir dan doa-doa yang langsung ditujukan kepada yang Mahakuasa-hal ini menjelaskan tentang adanya fenomena peristiwa hijrah, yaitu hijrah dari kebudayaan yang bernuansa kesyirikan menuju kebudayaan yang memiliki spirit ketauhidan.

\section{Keshahihan Hadist}

Hadist ini diriwayatkan oleh Imam Bukhari dalam Kitab Iman no 52. Para perawinya adalah Abdullah bin Maslamah bin Qa'nab. Nama julukannya (kuniyah) adalah Abu Abdurahman. Tinggal di Madinah. Beliau berasal dari kalangan Tabi'ut tabiin kalangan biasa. Dan wafat pada tahun $179 \mathrm{H}$. Menurut penilaian Ibnu Hibban, ia termasuk ast-tsiqaat, sementara Ibnu Hajar menyebutkan ia tsiqah dan ahli ibadah. Sedangkan Abu Hatim menyebutkan ia tsiqah hujjah.

Perawi berikutnya adalah Malik bin Anas, dari tabiut tabiin kalangan tua. Julukannya adalah Abu Abdullah. Tinggal di Madinah. Dan wafat tahun 179 H. Para ulama hadist, seperti Yahya bin Ma'in berpendapat ia tsiqah, serta Muhammad bin Sa'd menyebut ia tsiqah ma'mun.

Selanjutnya adalah Yahya bin Said, dari kalangan tabiin kalangan biasa. Nama julukannya Abu Said. Tinggal di Madinah. Dan wafat tahun 144 H. Para ulama, seperti
Ya'kub Ibnu Syaibah dan Adz Dzahabi menyebutnya tsiqah.

Berikutnya adalah Muhammad bin Ibrahim, dari kalangan tabiin biasa. Nama julukannya adalah Abu Abdullah. Tinggal di Madinah. Dan wafat tahun $120 \mathrm{H}$. Sejumlah ulama menyebutkan bahwa Yahya bin Said memiliki sifat tsiqah, seperti Ibn Sa'ad, Abu Hatim, Abu Zur'ah, Yahya bin Ma'in hingga Adz Dzahabi.

Lalu Alqamah bin Waqash bin Mihshan, ia dari tabiin kalangan tua. Tinggal di Madinah. Tidak diketahui tahun wafatnya. Namun demikian, para ulama seperti Ibn Hibban menilai bahwa Alqamah masuk dalam kategori Ats-Tsiqah, AnNasai menilainya tsiqah dan Ibn Hajar menyebutnya Tsiqah tsabat. Dan terakhir adalah Umar bin Khattab yang berasal dari kalangan sahabat utama sehingga tidak diragukan lagi kapasitasnya.

Maka, berdasarkan penilaian para perawinya yang semuanya berkategori minimal adalah tsiqah, dan tidak satupun di antara para perawinya yang cacat secara kompetensi dan kapasitas, hadist tentang niat dan hijrah menuju jalan Allah dan Rasul-Nya ini bisa dikatakan berkategori shahih. Di samping diriwayatkan oleh Imam Bukhari, hadist ini juga diriwayatkan oleh Imam Muslim, Abu Daud yang juga berkategori shahih.

Karena itu, berdasarkan uji hadist di atas yang diketahui berkategori shahih, maka tradisi rokatan yang telah mengalami perubahan niat dan unsur-unsur perbuatan yang telah bernilai islam tersebut sehingga memiliki kesesuaian dengan hadist tersebut, bisa dikatakan memang tidak bertentangan dengan ajaran Islam.

\section{Meneliti dari Lafal Periwayatan Hadist}

Melalui rangkaian para perawinya (sanad), hadist ini menggunakan simbol/lafal periwayatan yang memiliki bobot yang tinggi. Hal ini dikarenakan digunakannya simbol 'haddastana', dan 'akhbarana' dalam transmisi (periwayatan) hadistnya. Dalam kaidah periwayatan hadits, digunakannya simbol 'haddastana' dan 'akhbarana', bermakna sang perawi mendengar langsung hadits tersebut dari sang guru. 
Dalam hal ini, Imam Bukhari menggunakan 'haddastana' ketika menjelaskan ia memperoleh hadist dari Abdullah bin Maslamah. Sementara Abdullah bin Maslamah menggunakan lafal 'akhbarana', ketika menjelaskan pemerolehan hadistnya dari Malik bin Anas.

Dilihat dari masa hidupnya, Imam Bukhari memiliki hidup yang se-zaman dengan Abdullah bin Maslamah. Imam Bukhari lahir pada 194 dan wafat pada 256 $\mathrm{H}$, sementara Abdullah bin Maslamah wafat pada $221 \mathrm{H}$. Ketika Abdullah bin Maslamah wafat, usia Imam Bukhari menginjak 27 tahun.

Selanjutnya, dari posisi Malik bin Anas, lafal pemerolehan hadist menggunakan lafal 'an. Hal ini terus berlanjut pada perawi berikutnya, yaitu Yahya bin Said, Muhammad bin Ibrahim, Alqamah bin Waqash dan sahabat Umar bin Khattab. Dalam hal ini, penggunaan ' $a n$ ', menjelaskan posisi perawi yang bisa saja mendengar sendiri atau tidak mendengar sendiri hadist tersebut. Dengan kata lain, terdapat kemungkinan bahwa Malik bin Anas tidak mendengar langsung dari Yahya bin Said. Demikian juga Yahya bin Said hingga Alqamah bin Waqash dengan sahabat Umar bin Khattab.

Karena perawi tidak diketahui secara jelas apakah ia mendengar langsung ataukah tidak, Imam Bukhari dan pada mutaqaddimin memberikan syarat tertentu agar hadist yang disampaikan tersebut dapat diterima, yaitu (1) sang perawi bukan seorang mudallis, yaitu seseorang yang suka menyembunyikan cacat suatu sanad hadist, (2) perawi haruslah pernah berjumpa dengan guru yang pernah memberi hadist.

Kalau kita perhatikan dari tahun wafatnya Malik bin Anas, yaitu pada tahun $179 \mathrm{H}$, sementara Yahya bin Said wafat pada $144 \mathrm{H}$, dapat dikatakan bahwa Malik bin Anas hidup sezaman dengan Yahya bin Said. Demikian pula Yahya bin Said, memiliki hidup yang sezaman dengan Muhammad bin Ibrahim yang wafat pada $120 \mathrm{H}$. Di samping masa yang se-zaman, posisi para perawi dengan lafal 'an tersebut diperkuat dengan penilaian para ulama pada masing-masing perawi yang mendudukkan mereka pada posisi yang kesemuanya memiliki integritas yang kuat.

Dalam hal ini, Malik bin Anas dinilai oleh para ulama bahwa dia ia tsiqah hingga tsiqah ma'mun. Yahya bin Said yang dinilai tsiqah. Muhammad bin Ibrahim. Sejumlah ulama menyebutkan ia memiliki sifat tsiqah. Lalu Alqamah bin Waqash bin Mihshan, para ulama menilainya Ats-Tsiqah. Dan terakhir adalah Umar bin Khattab yang berasal dari kalangan sahabat utama sehingga tidak diragukan lagi kapasitasnya.

\section{PENUTUP}

Sebagai tradisi yang telah berlangsung selama berabad-abad lalu yang berkembang di Madura, tradisi upacara rokat pamengkang telah mengalami proses islamisasi. Dalam hal ini, proses islamisasi terutama berakar pada sumber niat atau motivasi yang melandasi diselenggarakannya upacara adat rokatan pamengkang, yaitu mengharap keselamatan dan keberkahan atas tanah warisan leluhur, agar nantinya tidak menimbulkan bencana bagi para pewarisnya.

Dalam hal ini, hadist No 52 yang diriwayatkan oleh Imam Bukhari dalam kitab Iman, di mana juga diriwayatkan oleh Imam Muslim No, 3530 dalam kitab Kepemimpinan, memberikan penegasan atas proses islamisasi uparaca rokat pamengkang sebagai tradisi yang telah menghidupi masyarakat dan menjadi sarana memperkuat keimanan dalam kehidupan sehari-hari.

Tradisi rokat pamengkang juga menjelaskan usaha para ulama terdahulu untuk melakukan proses pribumisasi islam yang bersanding dengan kebudayaan setempat, yang kini bisa diuji berdasarkan keilmuan penggalian hadist yang dikenal dengan istilah dengan living hadist, sehingga Islam sebagai agama yang memberi rakhmat bagi semua alam semakin terasa napasnya di semua bentuk kebudayaan di dunia. 
84 Upacara Rokat...

\section{DAFTAR PUSTAKA}

M Taufik Mandailing, Islam Kampar: Harmoni Islam dan Tradisi Lokal, Idea Press, Yogyakarta, 2012

Arifuddin Ismail, Agama Nelayan: Pergumulan dengan Budaya Lokal Yogyakarta, Pustaka Pelajar, 2012

Abdurrahman, Penegakan Amar Ma'ruf Nahi Munkar dalam Pelaksanaan Ritual Rokat Tase' di Kabupaten Pamekasan, Jurnal Ahsana Media, Vol. 6. No.2, Juli 2020

Soegianto, Kepercayaan, Magi dan Tradisi dalam Masyarakat Madura, Jember, Tapal Kuda, 2003

Ahmad Naufal, Rokat Pamengkang di Madura, Ikhtiar Merawat Islam dan Tradisi, Alif.id, Minggu, 30 September 2018

Ensiklopedi Hadist-Kitab 9 Imam Aplikasi Lidwa, Saltanera

Ignas Goldziher, Introduction to Islamic Theologi and Law, New Jersey, Princeton University Press, 1981

Minhaji, Kontroversi pembentukan Hukum Islam, terj. Ali Masrus Yogyakarta: UII Yogyakarta, 2001 